\title{
Record number of unmatched medical
}

\section{graduates}

\author{
— Cite as: CMAJ 2017 May 29;189:E758-9. doi: 10.1503/cmaj.1095432
}

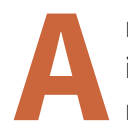
record number of Canadian medical graduates didn't match to a residency program this year. Meanwhile, the Canadian Resident Matching Service (CaRMS) reported a spike in unfilled family medicine positions in Quebec.

Sixty-eight Canadian medical graduates were unmatched after the second iteration of the 2017 CaRMS R-1 Match, up from 46 last year and 11 in 2009. "It's the highest number in at least a dozen years," says CaRMS CEO John Gallinger.

At the same time, 64 residency positions remained unfilled; 56 were in family medicine, all of which were in Quebec.

Medical students say the situation is deeply alarming and unacceptable. In a press release, the Canadian Federation of Medical Students urged universities to provide unmatched graduates with postmatch options, as well as peer-to-peer support and networking opportunities.

"While the underlying causes of this problem may not yet be fully understood, what is clear is that the current system is not only failing medical students, but also the future of Canadian health care," said Henry Annan, the federation's president-elect.

Gallinger agrees that the high number of unmatched Canadian medical graduates is an "undesirable outcome of the entire system." This year, there seems to be an "alignment issue where folks' first choice interest isn't aligned with where there are positions," he says. Many of the people who were unmatched after the first iteration had sought positions in internal medicine. For the first time in at least a decade, "more applicants chose that discipline as their first choice than there was supply of positions available," Gallinger explains.
There was also an increase in applications to surgical disciplines, and particularly to highly competitive positions, he says. That dovetailed with a slight decrease in demand for family medicine. About 34\% of Canadian medical graduates picked the discipline as their first choice, down from a peak of 38.5\% in 2015.

For the second year in a row, all unfilled family medicine positions after the second iteration of the match were in Quebec. Université Laval fared worst with 30 empty spots, followed by 17 at Université de Montreal, seven at Université de Sherbrooke, and two at McGill.

"It's quite unusual to have this many positions unfilled, particularly after the second iteration," says Dr. Nancy Fowler, executive director of academic family medicine with the College of Family Physicians of Canada.

Paradoxically, "Quebec medical students are still choosing family medicine at some of the highest rates in the country," she says. "They just didn't choose to stay in Quebec."

Normally, having some empty spots isn't a bad thing, says Dr. Matthieu Touchette, vice dean of postgraduate medical education at Université de Sherbrooke. "It permits us to be more flexible about transfers from other programs and about foreign doctors." Sherbrooke has

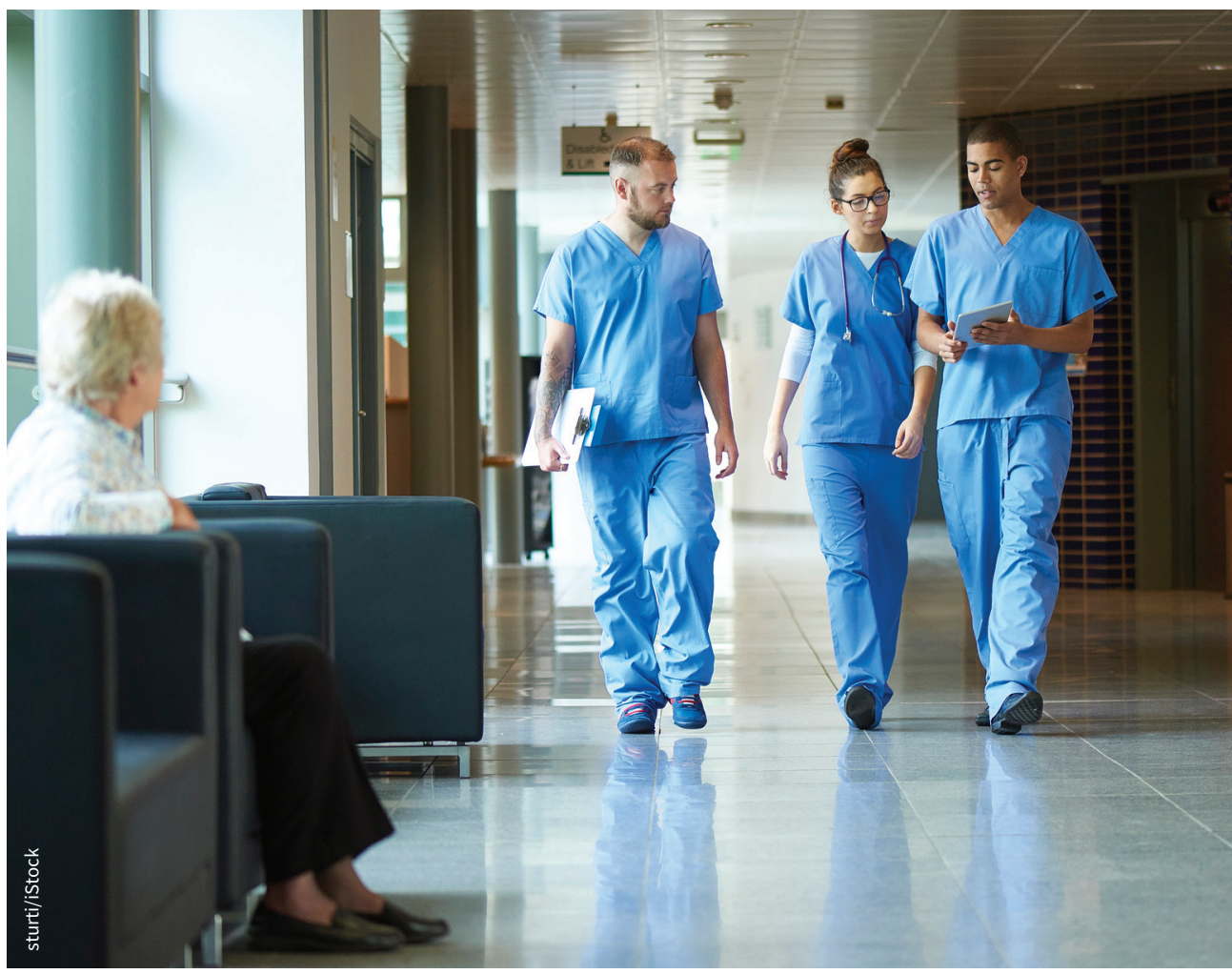

Increasing numbers of Canadian medical graduates aren't matching to residency programs while family medicine spots in Quebec remain empty. 
already filled most of its empty positions this way. But the situation is more worrying at Laval with 30 unfilled positions, he says. "Even with the transfers and everything that will be difficult to fill."

The number of empty family medicine positions in Quebec has more than doubled since 2014, when there were 22 empty spots.

"Clearly, there's something going on and we need to roll up our sleeves," says Dr. Maxine Dumas-Pilon, president of the Quebec College of Family Physicians. She attributes the problem to recent health care reforms and restrictive regional medical resource plans which determine where new physicians are permitted to practice.

"Most cities have been locked in terms of how many permits can be given, the aim being to reverse the trend of everyone working in cities," Dumas-Pilon explains. "It's a noble aim, but on an individual basis it has become complex for graduates to pursue what they want to do."

This may explain the high number of unfilled positions at Laval, since Quebec City doesn't have a lot of permits for new graduates, she says. "If you hear your friends graduated and had to go to the end of the world to practice, and you're from Quebec City, you might choose endocrinology so you can stick around."

Touchette agrees that changing restrictions and requirements for family doctors have likely discouraged trainees from pursuing family medicine in Quebec. "If I put myself in the place of a student, of course I would be worried."

He argues the provincial government needs to clarify how reforms will affect family practice in the years ahead. "For the universities, it's not easy for us to make family medicine attractive when we still have these uncertainties."

Lauren Vogel, CMAJ 